\title{
https://doi.org/10.36396/MS.2019.14.03.011
}

\section{Клинический случай гигантской аневризмы правой коронарной артерии}

А.^. КОМАРОВ 1 Ю.А. ФЕАОТКИНА' B.M. МИРОНОВ ${ }^{1}$, Г.К. АРУТЮНЯН ${ }^{1}$, Е.П. ПАНЧЕНКО

'ФГБУ «Национальный медицинский исслееовательский центр карииологии» Минздрава России, Москва, Россия

ПреАставлен кминический разбор больного с ишемической болезнью сердца, многососуиистым поражением коронарного русла и гигантской аневризмой коронарной артерии. Рассмотрены возможные подходы к выбору медикаментозного и инвазивного лечения.

Кıючевые слова: аневризма коронарной артерии, антикоагуяянтная терапия, ирескожное коронарное вмешательство, стент-граф

Clinical case of giant aneurysm of the right coronary artery

A.L. KOMAROV', A.YU. FEDOTKINA', E.V. MERKULOV', I.V. FEDOTENKOV

V.M. MIRONOV', G.K. ARUTYUNYAN', E.P. PANCHENKO'

'National medical research center of Cardiology of the Ministry of health of the Russian Federation, Moscow, Russia

There was presented a clinical discussion of the patient with coronary heart disease, multivessel coronary artery disease and huge aneurysm of coronary artery. Potential approaches to selecting conservative and invasive treatment were discussed.

Keywords: coronary artery aneurysm, anticoagulant therapy, percutaneous coronary intervention, stent graft.

Сведения об авторах:

А.А. Комаров - А.м.Н., Н.С. отАела КАинических проблем атеротромбоза Института киинической кардиологии им. А.А. Мясникова ФГБУ

«НМИЦ карАиологии» Минздрава России; тел.: (903) 711-62-39; e-mail: juliafedotkina@mail.ru

Е.В. Меркулов - А.м.н., С.н.с., заведующий 1-м отАелением рентгенхирургических методов диагностики и мечения ФГБУ «НМИЦ кардиологии» Минзарава России

И.С. Фемотенков - к.м.н., зав. кабинетомрентгеновской компьютерной томографии отАела томографии

В.М. Миронов - к.М.н., врач по рентгенэндоваскулярным Аиагностике и лечению ФГБУ «НМИЦ карАиологии» Минздрава России

Г.К. Арутюнян — врач по рентгенэнцоваскуяярным Аиагностике и лечению ФГБУ «НМИЦ кардиологии» Минздрава России

Е.П. Панченко - А.м.н., профессор, руководитель отАела киинических проблем атеротромбоза ФГБУ «НМИЦ кардиологии» Минздрава России

Аневризматическое расширение коронарных артерий (АКА) встречается относительно редко [1-5]. Так, при аутопсии лиц, умерших от различных причин, в том числе не связанных с сосудистой патологией, аневризмы
обнаруживаются в $1-2 \%$ случаев. По данным ангиографических регистров, частота выявления данной патологии составляет от 3 до $5 \%$

В соответствии с принятой классификацией $[1,6]$ об АКА принято говорить в том случае, когда диаметр расширенного сегмента артерии превышает диаметр соседнего «нормального» сегмента более чем в 1,5 раза. Аневризмы с диаметром более 20 мм считаются гигантскими В зависимости от соотношения продольного и поперен-

ОКомекктив авторо ного размеров различают мешотчатые и веретенообразные аневризмы. Для последнего варианта (особенно случае одновременного вовлечения нескольких сосудистых сегментов) более уместен термин «эктазия», харак-

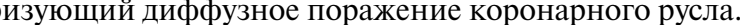
Как правило, патогенетическим субстратом для возникновения АКА является повреждение среднего слоя сосудистой стенки под действием протеолитических ферментов, выделяемых клетками воспаления. Причины такого повреждения весьма разнообразны и включают в первую очередь атеросклероз с экстенсивным ремоделированием коронарной артерии, воспалительныс заболевания (например, синдром Кавасаки, системные заболевания соединительной ткани), а также прямое заболейлие сосде сосудистую стенку того или иного инфек
Рисунок 1. Наибомее частые патогенетические механизмы развития АКА [6] ПКА за периол с 2013 по 2018 гол

\begin{tabular}{|c|c|c|}
\hline Этиология & Патогенетические механизмы & КАинические примеры \\
\hline Генетическая предрасположенность & $\begin{array}{l}\text { Специфический HLA (Human Leukocyte Antigens) класс } \\
\text { II генотип: НLA-DRB1*13, DR16, DQ2 bDQ5 }\end{array}$ & ИАиопатические АКА \\
\hline $\begin{array}{l}\text { Активаиия ферментов, участвуюших } \\
\text { в разрушении межклетонного } \\
\text { матрикса }\end{array}$ & $\begin{array}{l}\text { Реакция воспаления и протеолиз межккеточного } \\
\text { матрикса при атероскиеротическом поражении } \\
\text { коронарного русла }\end{array}$ & $\begin{array}{l}\text { АКА при атероскиеротическом } \\
\text { поражении коронарного русла }\end{array}$ \\
\hline $\begin{array}{l}\text { Аутоиммунные и воспалительные } \\
\text { заболевания }\end{array}$ & $\begin{array}{l}\text { Повышение уровня алгезивных молекул-1, } \\
\text { Е-селектина, дисбаланс межыу уровнями ММП } \\
\text { (матричные метамопротеиназы) и их тканевыми } \\
\text { ингибиторами }\end{array}$ & $\begin{array}{l}\text { Системные васкулиты (болезнь } \\
\text { Кавасаки, болезнь Такаясу), сифилис }\end{array}$ \\
\hline \multirow[b]{2}{*}{ Поврежьение сосуАистой стенки } & $\begin{array}{l}\text { Эпизоды повышения давления и вазоконстрикции } \pm \\
\text { поврежАение энцотелия }\end{array}$ & Употребление кокаина \\
\hline & $\begin{array}{l}\text { Воздействие механического фактора ими высокой } \\
\text { скорости потока крови }\end{array}$ & $\begin{array}{l}\text { Ятрогенное поврежАение во время } \\
\text { эндоваскулярных процедур. } \\
\text { Постстенотические аневризмы }\end{array}$ \\
\hline Вмияние инфекционных агентов & $\begin{array}{l}\text { Прямая инвазия инфекционных агентов в сосудистую } \\
\text { стенку. } \\
\text { Накопение в стенке иммунных комплексов }\end{array}$ & $\begin{array}{l}\text { Бактериальные, грибковые инфекции, } \\
\text { сифими, болезнь Аайма, септические } \\
\text { эмболии }\end{array}$ \\
\hline
\end{tabular}

ческие механизмы возникновения АКА представлены риантах «идиопатической коронарной артериопатии», связанной с генетической предрасположенностью к развитию аневризм.

Клинические проявления и прогноз АКА обычно зависят от заболевания, непосредственно приведшего к их возникновению. У больных с атеросклеротическим генезом аневризм наиболее частым симптомом является стенокардия [7-9], встречающаяся, впрочем, и при АКА, ассоциированных с другой патологией. В литературе описаны крайне редкие случаи одышки, сдавления прилежащих структур (правые отделы сердца, нижняя полая вена, пищевод и т.д.), а также разрывов тигантских АКА [10-14]

$У$ пациентов с ишемической болезнью сердца (ИБС) наличие сопутствуюших АКА является независимым предиктором смертельных исходов [6, 15-17]. Одна из причин неблагоприятного влияния на прогноз связана с высокой вероятностью тромбирования аневризм и развитием острого коронарного синдрома (ОКС), вызванного окклюзией крупной ветви артерии либо эмболией дистального сосудистого русла фрагментами тромботических масс, вымываемых из аневризматического мешка. Продемонстрированы также худшие результаты чрескожного коронарного вмешательства (ЧКВ) [18-20], обусловленные как частым развитием синдрома no-reflow за счет дистальной эмболии, так и высоким риском тромбоза стента в связи с отсутствием возможностей для его оптимального позиционирования в месте АКА.

Специальных предписаний по лечению пациентов с ИБС с аневризматическими изменениями коронарных артерий нет. В первую очередь это обусловлено относительной редкостью АKА и невозможностию организовать соответствуюшие рандомизированные испьтания Вместе с тем совершенно очевилно, что наличие данной тактики лечения коронарной болезни сердща В настолшем клиническом разборе мы сочли нелесообразным в табл. 1. Нельзя забывать и об относительно редких вапатологии догжно приниматься во внимание при выборе обсудить современные подходы к инвазивному и медика-

Больной М., наблюдается в НМИЦ кардиологии с 2003 года, когда в возрасте 40 лет без предшествующе клиники стокардии перенес инфаркт миокарда нижне локализации. В том же году была выполнена коронаронарного русла, послужившее основанием для хирургического лечения: маммарокоронарный шунт к переднеи межжелудочковой артерии, секвенциальный венозный (ATK), венозный шунт к задней межжелудочковой ветв (ЗМЖВ) правой коронарной артерии (ПКА). После операции получал стандартную терапию, включавшую бета-блокаторы, аспирин и статины.

Стенокардия возобновилась в 2013 году, спустя 10 лег функционировать, обнаружены окклюзия шунта к ЗМЖВ с хорошим заполнением дистального русла через межсистемные коллатерали, а также значимый стеноз секвенциального шунта, потребовавший выполнения ЧКВ. В течение 5 лет, с 2013 по 2018 год, у больного несколько условленные прогрессированием атеротромбоза в указанном шунте, а также в нативном коронарном русле. Трижды выполнены ЧКВ шунта к ДА и АТК. Четвертое по счету эндоваскулярное вмешательство было выполнено в июн 2018 года на проксимальном сегменте огибаюшей артерии Результаты реваскуляризации представлены на рис. $\mathbf{1 .}$

Как видно, была достигнута адекватная реваскуляризация бассейна левой коронарной артерии. Антеградный кровоток в ЗМЖВ из ПКА практически не визуализировался, ее кровоснабжение осушествлялось только чере межсистемные коллатерали. Возможно, послелний фак обусловливат сохранение у больного стенокарнии на уровне I-II функционального класса. ментозному лечению больного с ИБС с сопутствующи аневризматическим поражением коронарных артерий. графия, обнаружено многососудистое поражение корошунт к диагональной артерии (ДА) и артерии тупого края после коронарного шунтирования. Тогда же была повторена коронарография: маммарный шунт продолжал хорошо раз отмечены эпизоды ОКС без подъема сегмента ST, об- 
Следует обратить внимание на наличие аневризматических расширений коронарных артерий (на рис. 1 укааны стрелками), наиболее значительное из которых относилось к бассейу ПIКА. Заменим, что аневризм были виерые обнаружены у больного при исходном ко-

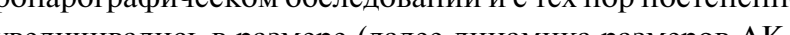
увеличивались в размере (далее динамика размеров АКА бсуждается нами более подробно)

Описанный нами случай достаточно типичен. Так, известно, что АКА чаще обнаруживаются у мужчин, при этом, как и в обсуждаемом клиническом примере, поражается преимущественно ПКА [1-6]. Считаем уместным еще раз напомнить, что тромбоз АКА служит частой причиной ОКС $[6,15-17]$. В этой связи весьма логично предположить взаимосвязь аневризмы ПКА и перенесенного инфаркта миокарда нижней локализации у представляемого больного.

Показано, что плохой контроль «классических» сосудистых факторов риска способствует формированию АКА. Применительно к обсуждаемому пациенту отметим продолжение курения и неоптимальный уровень липидов крови, требовавший назначения высокой дозы статинов в том числе с учетом их противовоспалительного действия. Полагают также, что помимо статинов лечени должно включать ингибиторы ангиотензинпревращающего фермента, в связи с участием указанного фермента в реакциях воспаления и протеолиза межклеточного марикса [21].

Раннее развитие ИБС, неоднократные эпизоды прогрессиров ния стиокардй, а также оाшанные выше особенности коронарной анатомии обусловливали необходимость поиска и других факторов риска, в первую очередь аутоиммунной патологии (см. табл. 1). Больной отмечал неоднократные эпизоды фотосенсибилизации в летнее время с формированием на лице типичных эритематозных участков в виде «бабочки». В 2013-2014 годах был обследован в НИИ ревматологии, где установлен диагноз дискоидной формы системной красной волчанки (СКВ). Детальное обсуждение диагностики и специфической терапии СКВ не входит в задачи настояшей работы. Отметим лишь, что лабораторная активность воспалительного процесса была низкой, данных о сопутствующем антифосфолипидном синдроме (АФС) не было, и ревматологи сочли возможным ограничиться назначением Плаквенила, на фоне которого обострений СКВ не было.

Обсуждая медикаментозное лечение пациента, считаем нужным остановиться на применении антитромботических препаратов. Механизм тромбообразования в аневризматически расширенных коронарных артериях во многом напоминает таковой в ушке левого предсердия и венозной системе. Логично предположить, что, как и у больных с фибрилляцией предсердий, усиление антитромботической терапии за счет добавления второго антиагреганта не приведет к сушественному снижению риска тромбозов АКА. Полагают [4, 22, 23], что препиратами выбора при данной патологии могут быть антикоагулянты, опыт использования которых, к сожалению, ограничиваесся относительн небольшими наблюдательными исстелованиями и регистрами. Одно из наиботес
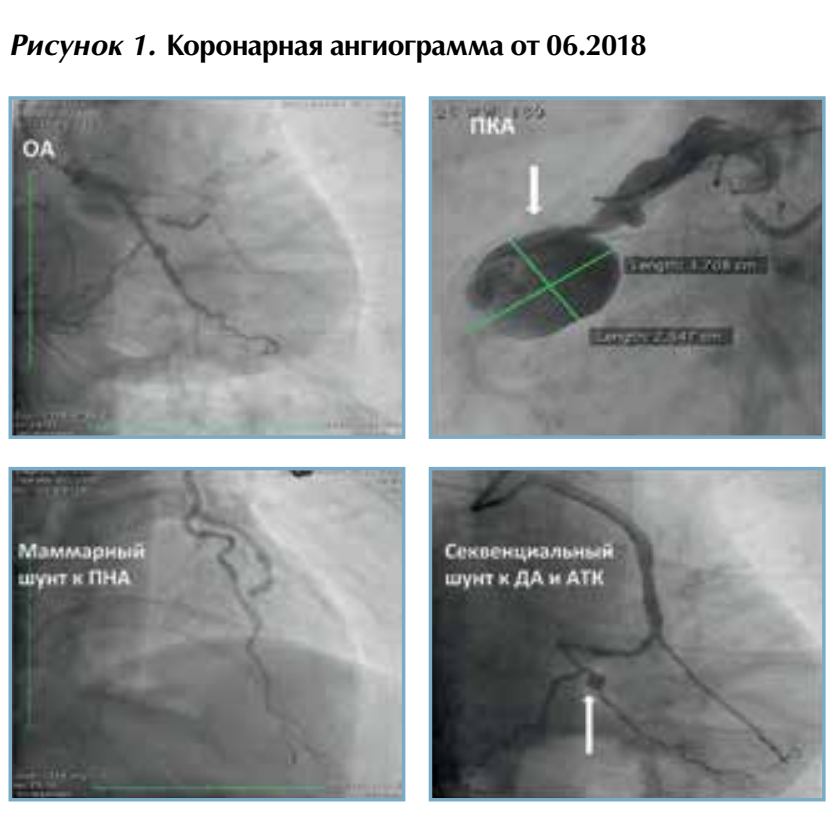

НА - передняя нисодЯая артерия, $\mathrm{OA}$ - огибающая артерия, ДА циагональная артерия, АТК - артерия тупого края, ПКА - правая кооннарная артерия. АКАуказаны стрелками

показательных исследований [17] включало 1698 больных с инфарктом миокарда, подвергнутых ангиографии с последующим инвазивным лечением. АКА были обнаружены в 51 (3\%) случае, и их наличие совершенно логично ассоциировалось с более чем трехкратным увеличением риска всех ишемических исходов, включая сосудистую смерть и нефатальный инфаркт миокарда, большинство случаев которого было связано с тромбозом аневризмы. Около $40 \%$ больных с АКА получали Варфарин, терапия которым оказалась высокоэффективна. в случае подлержания МНО (международное нормализованное соотношение) в терапевтическом диапазоне ни одного тромбоза зарегистрировано не было.

На сегодняшний день однозначные показания для назначения антикоагулянтов при АКА существуют лишь в отношении отдельных лиц с болезнью Кавасаки в случае больших или быстро прогрессирующих аневризм [24]. При сочетании ИБС и АКА (как в обсуждаемом клиническом примере) антикоагулянты, прежде всего Варфарин, также вполне допустимы, учитывая имеющийся опыт использования препаратов этой группы при вторичной профилактике ОКС [25, 26]. Дополнительным аргументом в пользу назначения Варфарина являлось наличие у обсуждаемого больного СКВ. При СКВ, сопровождаемой тромботическими осложнениями, Варфарин также может быть препаратом выбора, хотя, строго гворя, данное утверждение относится в первую очередь к случаям сопутствующего АФС [27].

Принимая во внимание все изложенное выше, в 2013 году больному был назначен Варфарин, прием ко торого продолжался в виде монотерапии либо в сочетании с одним или двумя антиагрегантами (в зависимости от давности выполненных ЧКВ). Как уже было отмечено за 5-летний период наблюдения, в течение которого боль- ной получал Варфарин, было зарегистрировано несколько эпизодов ОКС без подъема сегмента ST, закончившихся, однако, относительно благополучно. Естественно надеяться на абсолютную эффективность антикоагу лянтов было бы слишком оптимистично. Тем не менее,

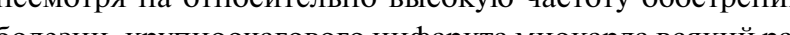
болезни, крупноочагового инфаркта миокарда всякий раз удавалось избежать. Таким образом, вполне правомочно предположение о том, что Варфарин относительно неплохо защищал больного от развития окклюзирующего тромбоза, несмогря на сочетание мнолес и ангиографических факторов риска.

Как уже было отмечено, после последней ЧКВ, обеспечившей вполне приемлемую реваскуляризацию миокарда, стенокардия при обычном режиме физической активности беспокоила редко. Однако начиная с лета 2018 года у больного появилась новая жалоба - одышка, не имевшая какой-либо связи с физической нагрузкой и не сопровождавшаяся ухудшением сократительной способности миокарда. В ходе обследования, направленного на поиск экстракардиальных причин одышки, была выполнена мультиспиральная томография грудной клетки с контрастированием сосудов. Единственной находкой оказалась гигантская, частично тромбированная аневриз ма среднего сегмента ПКА размерами 3,5 × 3,5 × 4,2см, по кровотоку - 1,8 x 2,4 × 2,6 см (рис. 2), контрастирование просвета ПКА за аневризмой практически отсутствовало. Аневризма компрессировала свободную стенку правых отделов сердца в проекции атриовентрикулярной борозды - на уровне трикуспидального клапана. Нельзя исключить, что сдавление аневризмой прилежащих структур было ответственно за развитие одышки. В доступной литературе приводятся сходные описания пациентов с гигантскими аневризмами ПКА, имевших аналогичную симптоматику [10-14]. Однако размеры аневризм и степень компрессии правых отделов сердца были выражень в значительно большей степени, чем у описываемого пациента.

При коронарографии оценить истинный размер аневризмы ПКА было сложно. Это связано как с частичным тромбированием аневризмы, так и с невозможно-

Рисунок 2. Муььтиспиральная компьютерная томография, многопмоскостная реконструкция. Гигантская аневризма ПКА с пристеночным тромбозом

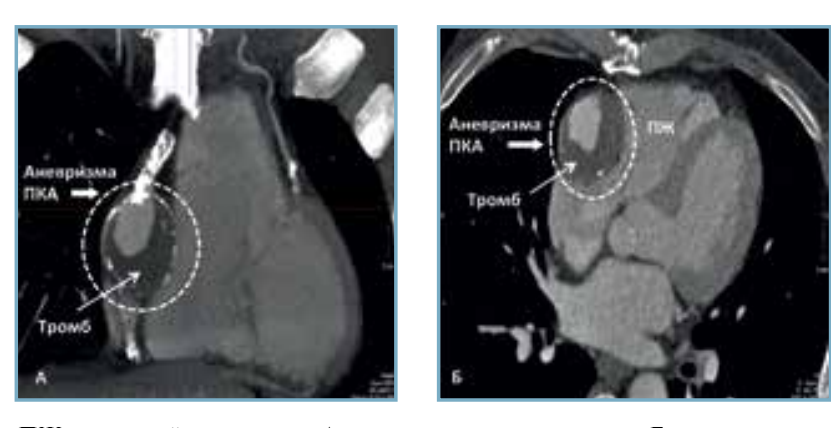

ПЖ - правый желудочек. А - корональная проекшия; Б - аксиальна проекция.
Рисунок 3. Аинамика размеров аневризм
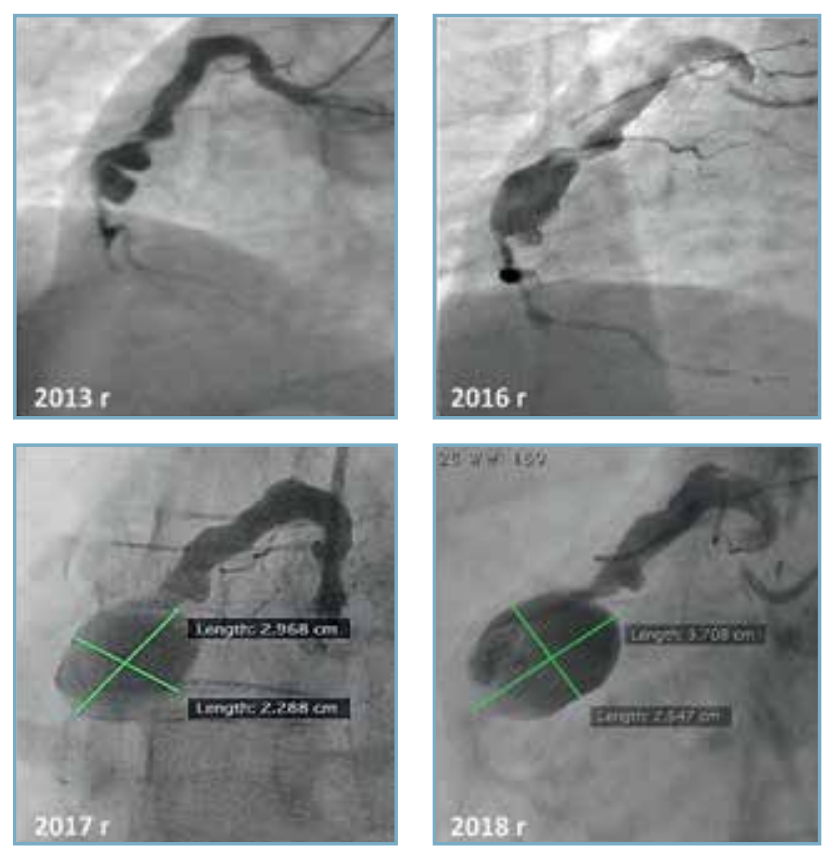

стью «тугого контрастирования» ее полости. Данный факт прин рекомендющими дополнительное использование внутрисосудистого ультразвукового исследования либо мультиспиральной компьютерной томографии с целью объективизации в отношении размеров и структуры стенок AKA [6]. Несмотря на описанные выше ограничения, мь сочли необходимым ретроспективно оценить динамику размеров аневризмы ПКА, используя архив данных коронарографии за 2013-2018 годы. Как показано на рис. 3, имелось очевидное увеличение как протяженности, тах и диаметра аневризмы с ухудшением визуализации дистального русла ПКА и ЗМЖА.

Факт компрометации кровотока дистальнее аневризмы, совершенно не означающий наличия окклюзии, отмечают многие авторы [6, 14]. Считается, что нарушение дистальной гемодинамики в первую очередь обусловлено турбулентностью потока и значительной потерей энергии при прохождении крови через аневризму. Таким образом, гемодинамические эффекты гигантских аневризм в известной степени близки к таковым у критических стенозов коронарных артерий.

По данным литературы, вероятность разрывов АКА крайне низка, даже в случае очень больших размеров, превышающих описанный нами в 2 раза и более $[6,28]$. Тем не менее, учитывая очевидную отрицательную ангиографическую динамику, потенциальную возможность дальнейшей компрометации правых отделов сердца, а также появление новых симптомов (одышка), возможно связанных с наличием аневризмы, принято решение о выполнении эндоваскулярного вмешательства с нель о выполнении эндоваскулярного вмешательства с целью Следует отметить, что данная процедура сопряжена с ря- 
дом технических сложностей и может быть успешно реализована лишь в условиях высокоспециализированного стационара [6]. Как уже говорилось, при манипуляции на аневризме велик риск дистальной эмболии с развитием синдрома по-геноw. Значительные размеры аневризмы и плохая визуализация ее стенки создают опасность дислокации стента, а также расслоения и даже перфорации сосуда. Ситуация усложняется еще и тем, что в протяженных аневризмах, как правило, требуется использование системы из нескольких стентов для покрытия всей ее длины. Критерием эффективности процедуры является отсугс Бие затеков крови в полость аневризмы добиться чего зачастую бывает весьма сложно. Процедура эндоваскулярной изоляции аневризмы ПКА представлена на рис. 4.

При контрастировании ПКА в среднем сегменте визуализировалось гигантское аневризматическое расширение. При этом дистальный сегмент ПКА не контрастировался (см. рис. 4, А). Для уточнения состояния дистального русла в ПКА был заведен гидрофильный интракоронарный проводник. Затем в аневризму по коронарному проводнику был заведен удлинитель катетера. Это позволило визуализировать дистальный сегмент ПКА. При контрастировании через удлинитель катетера в дистальном сегменте ПКА был выявлен 95\% стеноз. Было принято решение о стентировании дистального сегмента ПКА и попытке изоляции аневризмы. В месте стеноза в дистальном сегменте ПКА после предилатации баллонным катетером 3,0 x 15 мм был установлен стент с лекарственным покрытием эверолимус 3,5 х 20 мм. Далее в месте аневризмы в среднем и проксимальном сегменте ПКА последовательно установлень стент-графты, покрытые ксеноперикардом, размером 3,5 27 мм и 4,0 х 23 мм. При контрольном контрастировании в проксимальном сегменте аневризма была полностью вы- ключена из кровотока, однако в месте стыка стента с лекарственным покрытием и стент-графта визуализировался

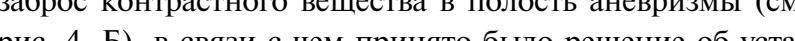
рис. 4, Б), в связи с чем принято было решение об установке дололнительного стент-графта 3,5 х 23 мм в месте затека. Далее выполнена постдилатация графтов ва все .

При контрольном контрастировании признаков сброса контрастного вещества в полость аневризмы не выявлено. ПКА проходима на всем протяжении (см. рис. 4, В) Следует также обратить внимание на хорошую визуализацию дистального русла ПКАи ЗМЖА, ставшую возможно благодаря устранению препятствий антеградному кровогоку, обусловленных значительными размерами аневризмы. Улучшение кровотока через ПКА сопровождалос практически полным устранением стенокардии. Одышка также постепенно стала уменьшаться и прошла через 4 мес. Терапию антикоагулянтами временно отменили с целью гарантированного формирования тромба и достижения олной окклозии аневризмы, изолированно стент-графтом. При контрольной мультиспиральной томографии (рис. 5), выполненной через 1 мес., сообщения между ПКА и изолированной полостью аневризмы не обнаружено. Полученные данные позволили возобновить лечение антикоагулянтами. Очевидно, что целесообразность их приема сохранится в течение неопределенно долгого времени, учитывая аневризмы других коронарных артерий, а также сопутствующую аутоиммунную патологию. Среди всех препаратов этой группь наиболее оптимальным представляется Варфарин, хотя c формальной точки зрения нет строгих запретов для его замены на более удобные и безопасные пероральные антикоагулянты прямого действия. Справедливо, однако, заметить, что опыт использования препаратов последней

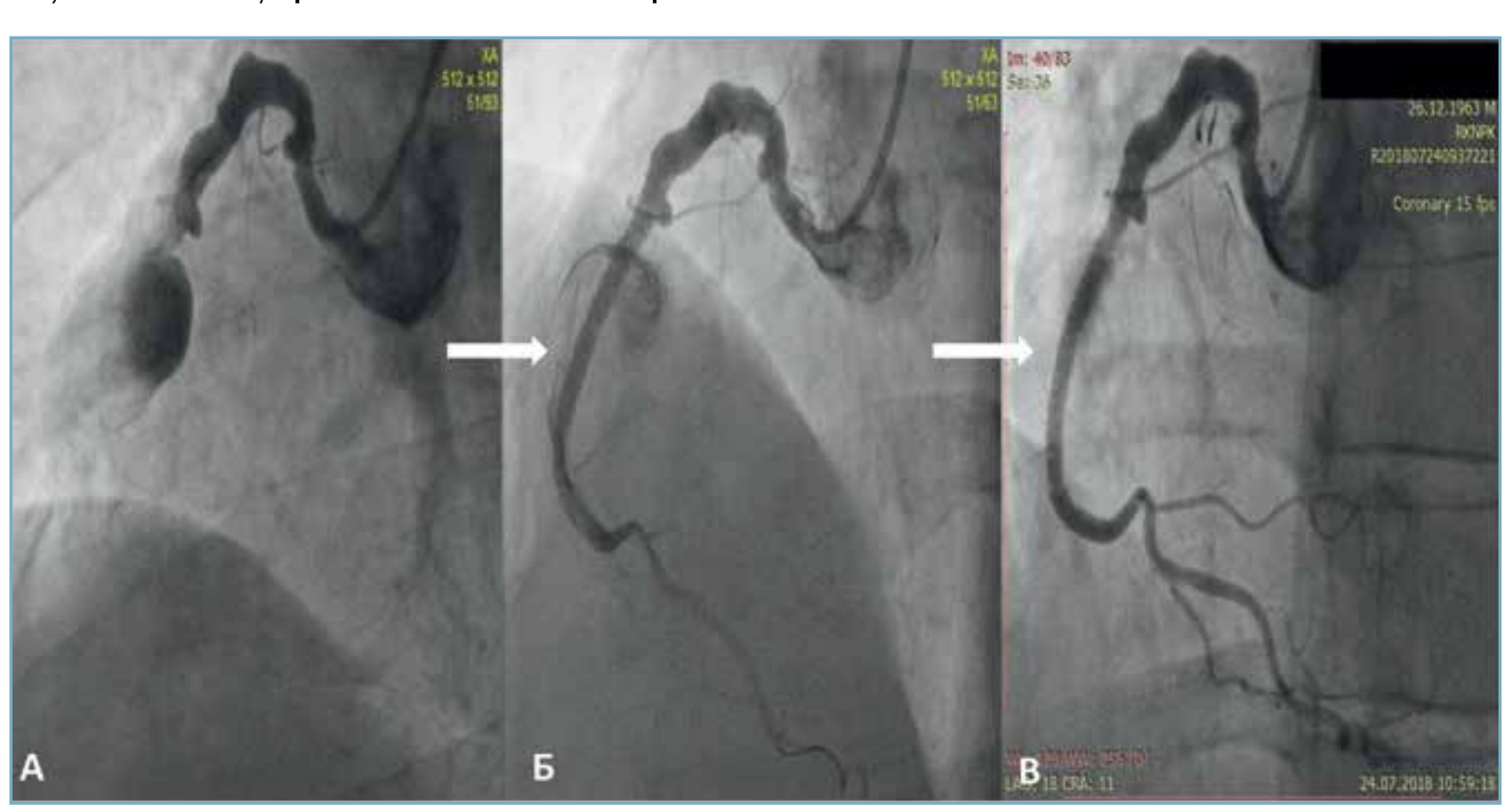

Рисунок 5. Мукьиспирахьная компьютерная томография, многопмоскостная реконструкция. Выполненная
изояяция гигантской аневризмы ПКА. А - корональная проекция; Б - аксиальная проекция
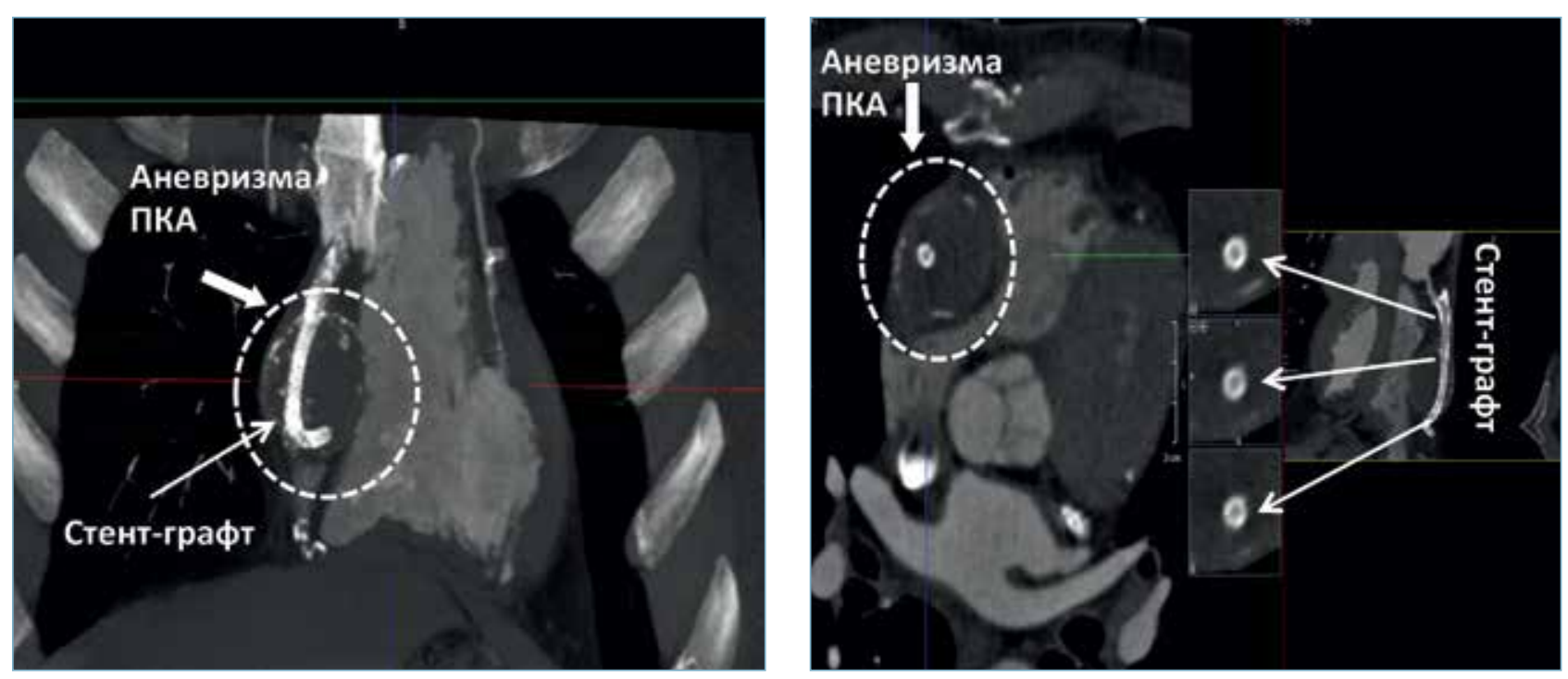

группы применительно к обсуждаемой патологии весьма ограничен. Известно лишь, что у лиц с высокой активностью АФС эффективность прямых пероральных антикоагулянтов (по крайней мере, Ривароксабана) в отношении профилактики тромботических осложнений меньше, чем у Варфарина [29].

K сожалению, поражение артерий часто носит системный характер с высокой вероятностью формирования аневризм в сосудистых бассейнах, отличных от коронарного $[6,14,28]$. В этой связи мы сочли необходимым дополнительно оценить состояние артерий головного мозга и аорты, аневризмы которых встречаются достаточно часто и могут иметь наиболее неблагоприятный прогноз. Была выявлена аневризма инфраренального отдела аорты с максимальным диаметром 3,2 см. Понятно, что относительно небольшая аневризма не требовала каких-либо инвазивных вмешательств и тем более не являлась препятствием к приему антикоагулянтов. Тем не менее с учетом возможного увеличения ее размеров очевидна необходимость динамической оценки ее размеров с интервалом $1-2$ раза в год.

\section{Заключение}

Редкая встречаемость АКА, а также отсутствие каких-либо клинических рекомендаций определяют актуальность представленного клинического случая, демонстрирующего подход к обследованию и лечению пациента с гигантской аневризмой ПКА. Несмотря на устрашающую ангиографическую картину гигантские AKA, как правило, не имеют каких-либо спешифических

клинических проявлений и не несут самостоятельной

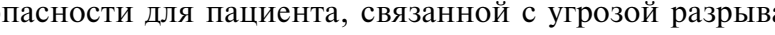
В то же время наличие АКА, безусловно, ухудшает проноз больных с коронарным атеросклерозом. Это связано с частыми тромботическими осложнениями, а также с нарушением дистального кровотока, скомпрометированного наличием аневризмы. Обнаружение АКА дае основание для модификации антитромботической терапии - назначение антикоагулянтов, прежде всег Варфарина. По нашему мнению, пациенты, у которых выявлены АКА, нуждаются в более тщательном обследовании и наблюдении. Такое обследование должно включать активный поиск заболеваний, способствующих возникновению АКА, а также оценку состояния других артериальных бассейнов на предмет наличия аневризм. Необходимо также предусмотреть динамическую оценку размеров АКА, предпочтительно с помощью мультиспиральной компьютерной томографии. Каких-либо признаков, определяющих высокий риск разрыва АКА, не описано. Тем не менее достижение аневризмой гигантских размеров, компрометация прилежащих органов, а также появление новой клинической симптоматики, которая не может быть объяснена какими-либо другими причинами, делает обоснованным хирургическое или эндоваскулярное лечение. В нашем случае описана эндоваскулярная изоляция АКА ПКА с использованием системы стент-графтов, которая позволила выключить полость аневризмы из кровотока и при этом сохранить кровоснабжение дистального сосудистого русла.

Авторы заявляют об отсутствии конфликта интересов. 
1. Swaye P.S., Fisher L.D., Litwin P., P.A. Vignola, M.P. Judkins, H.G. Kemp, J.G. Mudd, A.J. Gosselin. Anetrysmal coronary artery disease. Circulation

AssaadS. Daoud, David Pankin, Henry Tulgan, RudolfA. Florentin. Aneurysms
of the coronary artery. Report of ten cases and review of the literature. $A m$ Cardiol. 1963;11: 228. https://doi.org/10.1016/0002-9149(63) 90064-X ectasia in human coronary arteries in patients in Northern Greece referreed
forcoronary angiography. $A m \quad J$ Cardiol. 2006;98:314-318 https://doi

HartnellGG G. Parnell B M. Pridid

and clinical siginificance in in 4993 patients. Br He Heart J. 1985; $54(4)$ : $: 392$ - http: $/ /$

dx.doi.org/10.1136/hrt.54.4.3.32
John E. Markis, C. David Joffe, Peter F. Cohn, Dennis J. Feen, Michael V.

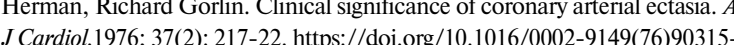

Akram Kawsara, Ivan J. Nuñez Gil, Fahad Algahtani, Jason Moreland Charanjit S. Rihal, Mohamad Alkhouli. Management of Coronary Artery jcin 201802041 . 041 .

Aboeata A.S., Sontineni S.P., Alla V.M., Esterbrooks D.J. Coronary artery
ectasia: current concepts and interventions. Front Biosci ilite Ed. 2012; 4 : 300-

Hyung Joon Joo, Cheol Woong Yu, RakKyeong Choi Jinsik Park, Hyun Jong Lee, Je Sang Kim, Young Jin Choi, Jae Hyoung Park, Soon Jun Hong, Do Sur Lin. Cinicaloutcomes of patients with coronary artery aneurysmatter the firis

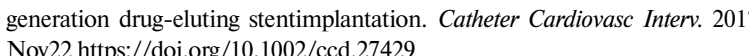

Polyetrafluoroethylene covered stent and coronary arterv aneurryms. Catheter

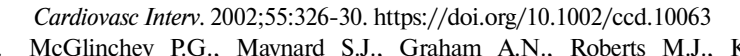
M.M. Giant aneurysm of the right coronary artery compressing the
rightheart. Circulation. 2005;112(4): $666-7$. https://doi.org/10.1161/ CIRCULATIONAHA.104.496224

L.H., Dangas G., Mehran R., Leon M.B. Prculation. 1999:100(1):E8-El1: 12. Li Di D., Wu Q., Sun L., Song Y., Wang W., Pan S., Luo G., Liu Y., Qi Z. Tao T., Sun J.Z., Hu S. Surgical treatment of giant coronary artery aneurysm
$J$ Thorac Cardiovasc Surg $2005 \cdot 130(3)-817-21$. htor jtcvs.2005.04.004

13. Mignosa C., Agati S., Bianca I., Salvo D., Pittella G., Ciccarello G

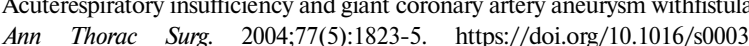
$4975(03) 01272-4$ 4. Абугов С.А., Сулимов В.А., Удовиченко А.Е. Аневризмы коронарных артерий: три ктинических случая. Международный журнал инV.A. Udovichenko A. E. Corongy attery Aneurgens three clinical cases International journal of interventional Cardioangiology. 2004; 6: 37-40]

5. Baman T.S., Cole J.H., Devireddy C.M., Sperling L.S. Risk factors and

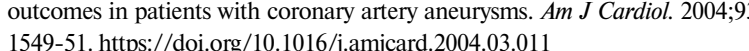

16. Takayuki Warisawa, Toru Naganuma, Nobuo Tomizawa, Yusuke Fujino,
Hisaaki Ishiguro, Satoko Tahara, Naoyuki Kurita, Takeshi Nojo, Shotaro Nakamura, Sunao Nakamura. High prevalence of and non-coronary events in patients with coronary artery aneurysm in the
observational group. Int I Cardiol Heart Vasc. 2016;:10:29-31. https://doi org/10.1016/.j.jcha.2015.10.00

. Takahito Doi, Yu Kataoka, Teruo Noguchi, Tasuhhiro Shibata, Takahiro
Nagai, Tomoaki Kanaya, Yoshio Tahara, Yasuhide Asaumi, Etsuko Tsuda,

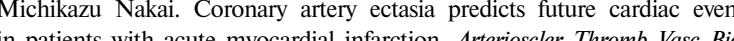
2017:37:2350-5. https://doi.org/10.1161/attbaha.117.30968.

18. Gokkturk Ipek, Baris Gungor, Mehmet Baran Karatas, Tolga Onuk, Muhammed Keskin, Ozan Tanik, Mert Ilker Hayiroglu, Ahmet Oz, Edibe Betul Borklu, related artery who underwent nimary nercut ST elevated myocardial infarction. Catheter Cardiovasc Interv. 2016;88:748-53.

httpps:///di.org//10.1002//ccd.26553
Bogana Shanmugan V., Psaltis P.J., Wong D.T.L., Meredith I.T., Malaiapan Y, evation myocardial infarction caused by ectatic infarct related arteries Lung Circ. 2017;26:1059-68. https://doi.org/10.1016/.hlc.2016.12.006 Hon-Kan Yip, Mien-Cheng Chen, Chiung-Jen Wu, Chi-Ling Hang, Kelv doutcome of coronary artery aneurysm in patients with acute myocard farction undergoing a primary percutaneous coronary intervention Cardiology. 2002,98.132-40. hips.//60i.org/10.1159/000066322

converting 2003;89:213-4. http://dx.doi.org/10.1136/heart.899.2.213

22. Usama Boles, Ying Zhao, Roby Rakhit, Man Fi Shiu, Alexandros Henein. Patterns of coromary atery ectasian, myocardial infarction. Scand Cardiovass J. 2014;48:161-6. https://doio.rog/10

$3109 / 14017431.2014 .902495$
3. Yan Zhang, Qiao-Juan Huang, Xiao-Lin Li, Yuan-Lin Guo, Cheng-Gang
Zhu, Xiao-Wei Wang, Bo Xu, Run-Lin Gao, Jian-Jun Li. Prognostic value of coronary arterystenoses, Markis artery ectasia. Cardiology. 2015; 131:251-9. https://doi. org/10.1159/000381702 Brian W. McCrindle, Anne H. Rowley, Jane W. Newburger, Jane C. Burns Masato Takahashi, Pinak B. Shah, Tohru Kobayashi, Mei-Hwan Wu, Tsutom T. Saji. Diagnosis, treatment, and long-term management of Kawasak

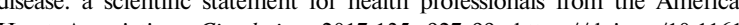

Hurlen M., Abdelnoor M., Smith P., Erikssen J., Arnesen H. Warfarin, aspirin or both after myocardial infarction. $N$ Engl I Med. 2002;347:969-74 https://dol Диагностика и лечение больных острым инфарктом миокарда с подъемом сегмента SТ ЭКг. Рекомендации ВНОК. Ред. Руда М.Я. Кардиоваскулярная терапия и профилактика. 2007; 6 (8), Приложение 1. С. 415 ST-segment elevation of the ECG. Recommendations of GFCF Red Ore $M$.

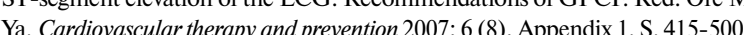
Ruiz-Irastorza G., Cuadrado M.J., Ruiz-Arruza I. Evidence-based in antiphospholipind antibody-positive patients: report of atask force at the 13t Interitionl Congress on antiphospholinid antibodies Lupus. 2011:20206-

218. https://doi.org/ $10.1177 / 0961203310395803$
Ramos S.G., Mata K.M., Martins C.C., Martins A.P., Rossi M.A. Giant right 2008 Sep-Oct: 17(5):329-33. doi: 10.1016/jicarrathac.2007.07.001.

29. Pengo V., Denas G., Zoppellaro G. Jose S.P., Hoxha A. Ruffatti A. Andree L., Tincani A., Cenci C., Prisco D., Fierro T., Gresele P., Cafolla A., De

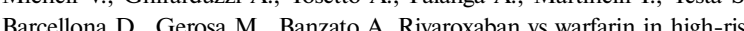
patients with antiphospholipid syndrome. Blood. 2018 Sep 27:132(13):13651371. doi: 10.1182/blood-2018-04-848333.

Поступила 01.02.2019 